\title{
CIÊNCIA E SUA INICIAÇÃO: ANOTAÇÕES PARA REFLEXÃO
}

\author{
Science and its initiation: notes for reflexion
}

Adriano Rodrigues Ruiz ${ }^{1}$

\begin{abstract}
Resumo: Nesta reflexão, de natureza ontológica, a ciência é identificada como ferramenta de coordenação do pensamento, necessária a todos, porém inacessível à maioria das pessoas. O espírito científico é apresentado como, ligado à superação de amarras provenientes do apego às explicações duráveis e ao governo desde fora. Os esforços de aproximação à ciência, no mundo escolar, são apontados como um desafio a estar presente em todos os níveis, do Ensino Fundamental à pós-graduação.
\end{abstract}

Unitermos: Ciência, aproximação à ciência, coordenação do pensamento.

\begin{abstract}
In this ontological reflection, science is identified as a thought coordination tool necessary to everyone, although not available to most people. The scientific spirit is presented as related to the overcoming of support proceedings from attachment to the lasting explanations and to the outside government. The efforts for approximation to school science are pointed out as a challenge to be present at all educational levels, from primary school to graduate studies.
\end{abstract}

Keywords: Science; approximation to science; thought coordination.

\section{Introdução}

Somos criadores de ferramentas e de tecnologias, o orgulho de nossos dias é o computador. Os esforços de universalização do instrumental tecnológico sempre são bem-sucedidos, vistosas vitrines exibem as maravilhas da tecnologia e as facilidades de acesso a elas.

$\mathrm{Na}$ construção de instrumentos de coordenação do pensamento, temos sido quantitativamente menos exuberantes: a última grande construção foi a ciência e a sua universalização é ainda muito precária. Ela continua distante e quase inacessível à imensa maioria das pessoas, sua iniciação continua limitada.

O educador, quando caminha para a iniciação à ciência, encontra-se em um campo em que a interrogação ontológica (o que é isso?) coexiste com a epistemológica (como tomamos conhecimento disso?). E, em relação a ambas, persistem dificuldades de bom porte.

O diálogo com os gigantes da ciência permite-nos pistas para "o que é isso?", possibilita identificar a ciência como ligada ao conhecer, ao processo de busca, à aventura prazerosa, à poética do intenso viver da construção de ferramentas de pensamento. Percebe-se, também, que o conhecimento armazenado pertence a outro domínio, é prosaico e frio.

A ferramenta principal do "como tomamos conhecimento disso?" é a pergunta. Ela nos conduz à formulação de hipóteses, à coordenação de possíveis evidências, ao crivo da razão e ao desapego às certezas. A ciência é convidativa à submissão, à prova em contrário, ao jogo entre nossas crenças e o que o mundo exterior exibe, à aceitação das limitações dos cinco sentidos, como ferramentas de conhecimento.

Nesta reflexão, tomamos a palavra "ciência" no sentido de processo, não de resultados. Assim, o vocábulo refere-se às atividades de perguntar, imaginar, observar, experimentar, organizar... O foco de nossas atenções é a questão ontológica.

${ }^{1}$ Professor doutor aposentado da Universidade Estadual de Maringá e docente do Programa de Mestrado em Educação daUnoeste.E-mail:arruiz@uol.com.br. 


\section{O que é ciência?}

Os matemáticos, os físicos e os biólogos hoje alimentam as mais fecundas discussões sobre a natureza do pensamento científico. (Jean Piaget)

Um caminho possível nesta busca é o da aproximação pela negação. Podemos começar dizendo que a ciência não é o acúmulo de conhecimento, não é uma coletânea de boas respostas, não é o registro de múltiplas experiências, não é a arte de combinar substâncias para atender oportunidades de mercado, não é a habilidade de compor bons relatórios para as agências de fomento... Contudo, o percurso da negação parece pouco iluminado. Sendo assim...

O que ela é, então?

Os gigantes da ciência vêem com olhos carinhosos e visionários essa atividade humana: um modo de viver, de dialogar com o mundo, de governar pensamentos, de confrontar crenças com dados empíricos... Vamos ouvi-los!

Prigogine e Stengers (1997, p. 203), ao falarem do reencantamento do mundo, dizem que a ciência, além de ser a arte de ler a natureza, é "um esforço para compreender, para responder a algumas questões que, de geração em geração, alguns homens não cessaram de colocar a eles mesmos". Entre essas questōes, está a da relação entre o ser e o devir, entre a permanência e a mudança.

Norbert Wiener (2000, p. 190) assevera ser

(...) a ciência um modo de vida que só pode florescer quando os homens têm liberdade para ter fé. Uma fé a que obedeçamos em razão de ordens que nos são impostas de fora não é fé, e uma comunidade que se coloque na dependência de uma pseudo-fé desse tipo está destinada a arruinar-se, ao fim e ao cabo, devido à paralisia que a falta de uma Ciência em salutar desenvolvimento lhe imporá.

Albert Einstein (1981, p. 138), retratando o fazer ciência, fala que a motivação do cientista "assemelha-se à nostalgia que atrai o morador das cidades para longe de seu ambiente ruidoso e complicado, para as pacíficas paisagens das altas montanhas, onde o olhar vagueia por uma atmosfera calma e pura e se perde em perspectivas repousantes, que parecem ter sido criadas para a eternidade".

Heisenberg (1990, p. 48) diz ser a ciência uma "viagem à abstração, análoga à viagem ao interior" que é visível na poesia, na pintura, na música e na filosofia. "No final da viagem não se encontrará vida ou o mundo natural, mas se observará uma melhor compreensão e a clareza em relação às idéias com as quais se constrói o mundo".

Para o físico Pierre Auger (2000), fazer ciência é o esforço de adaptação do sujeito para estabelecer correspondências precisas entre as idéias derivadas da sua estrutura interna e os fenômenos da natureza que o envolve. Assim, o rigor das idéias científicas está na correspondência entre as estruturas internas - a lógica e a matemática - e os fatos externos. Auger (2000, p. 104) argumenta: "a comparação das cadeias causais entre fenômenos exteriores com as cadeias lógicas interiores das idéias que lhes correspondem constitui, a bem dizer, o sistema científico". Ele acrescenta que, o fato de ser "submetido à comparação com o meio externo acarreta-lhe extrema sensibilidade a numerosas causas de mortalidade".

Jean Piaget (1998, p. 100) identifica a ciência como um instrumento espiritual que nos ajuda a compreender e atuar no mundo: 
A ciência é uma das mais belas adaptaçôes do espírito humano. Ela é uma vitória do espírito sobre o mundo material. Mas como ela vingou? Não foi apenas pela acumulação de conhecimento e experiências. Longe disso. Foi construindo uma ferramenta intelectual de coordenação, graças à qual o espírito pôde relacionar os fatos uns aos outros.

Bronowski (1998, p. 39-40) diz que a imaginação é um processo experimental, seja para a criança que brinca, seja para o poeta que procura encontrar um caminho mediante situaçôes humanas ainda não compreendidas, seja ainda para o físico que experimenta situações materiais não conhecidas. "Se a ciência é uma forma de imaginação, se todos os experimentos são uma forma de brincadeira, a ciência não pode ser tão séria assim..." Aos que se satisfazem em saber de cor os resultados das pesquisas, resta o papel de operários da ciência: competentes na execução de rotinas, mas desprovidos de imaginação criadora.

A ciência é, portanto, a conseqüência de um esforço milenar da humanidade para superar o egocentrismo intelectual que limita nossa compreensão de mundo. Diante da pergunta: "como o espírito humano se tornou capaz de compreender os fenômenos físicos?", Piaget argumenta que foi vivendo um processo, no qual, em cada etapa, o pensamento humano livrou-se de uma determinada forma de egocentrismo, caindo num egocentrismo mais refinado. A descentração crescente tem permitido avanços da objetividade na leitura da realidade.

Assim, diremos que a ciência é a ferramenta a qual permite coordenações intelectuais capazes de nos ajudar a transitar no largo nevoeiro de preconcepçôes que dificultam nosso diálogo com a realidade. A sua alma é a curiosidade que tornou necessária a compreensão deste vasto mundo e da natureza de suas coisas. Ela pertence ao território do olho imaginário que antevê caminhos, da fé criadora no humano e em suas possibilidades, da humildade para duvidar daquilo que parece ser verdade, da compreensão de que conhecer pode ser uma aventura fascinante... E uma atividade intelectual que aceita a mortalidade dos conhecimentos que ela própria constrói.

\section{Por que a ciência é necessária?}

O homem está por inventar-se. Contudo, para que cada homem tenha a possibilidade de se inventar a si mesmo é necessário criar uma nova sociedade, fundada menos na procura da eficácia do que na busca da lucidez. (Albert Jaquard)

A ciência conheceu seu alvorecer quando os gregos perceberam que o mundo à sua volta podia ser compreendido; para isto, bastava desenvolver boas e pacientes estratégias de observação, de experimentação e de reflexão. Schrödinger (1996, p. 58), a esse respeito, diz que, assim, eles descobriram que

(...) o mundo não servia de local de recreio a deuses, fantasmas e espíritos que agiam sob o impulso do momento e mais ou menos arbitrariamente, movidos por paixōes, por ira, por amor e por desejo de vingança, dando livre curso aos seus ódios e podendo ser apaziguados por ofertas devotas. Esses homens libertaram-se da superstição e não pactuaram com nada disso. Encararam o mundo como um mecanismo bastante complicado, que agia de acordo com leis inatas e eternas, e que eles tinham curiosidade em descobrir.

Diante desse mundo complicado e inteligível, o primeiro requisito para um cientista é ser curioso: e motivos para curiosidade não faltam. Schrödinger (1996, p. 99) lembra-nos que nascemos e fazemos parte de um ambiente - não sabemos de onde viemos nem para onde vamos, nem quem somos. 


\section{Adriano Rodrigues Ruiz}

A nossa questão premente tem a ver com a origem e com o destino - mas tudo que podemos investigar é o ambiente atual. Por isso temos necessidade de descobrir tanto quanto pudermos acerca dele. E esse esforço representa a ciência, a educação, o conhecimento. Essa é a fonte verdadeira das diligências espirituais do homem.

As relações que permitem a compreensão dos "fatos" são de natureza bastante complexa. O físico David Bohm (2001, p. 83), referindo-se à nossa ingenuidade a esse respeito, assevera:

(...) costuma-se acreditar que o conteúdo do pensamento encontra-se numa espécie de correspondência reflexiva com "as coisas reais", talvez uma cópia, ou imagem, ou imitação dos objetos, talvez um "mapa" das coisas, ou ainda (em conformidade com o que foi sugerido por Platão) uma apreensão das formas essenciais e mais íntimas das coisas.

Ele adverte-nos de que "o conteúdo do pensamento nada mais nos dá que "instantâneos" simplificados da realidade".

Por isso, instrumentos intelectuais de coordenação, que permitam a superação de nosso egocentrismo, fazem-se necessários. Schrödinger (1997) identifica as teorias científicas como ferramentas dessa natureza, as quais "são úteis para facilitar o exame de nossas observações e de nossos achados experimentais”. Bohr (1995, p. 30) recorda-nos da lição epistemológica, dada pela pesquisa física:

Nossa penetração no mundo dos átomos, antes vedado aos olhos do homem, é de fato uma aventura comparável às grandes viagens de descobrimento dos circunavegadores e às ousadas exploraçóes dos astrônomos nas profundezas do espaço celeste. Como se sabe, o maravilhoso desenvolvimento da arte da experimentação física não apenas eliminou os últimos vestígios da antiga crença em que a precariedade de nossos sentidos impediria permanentemente de obter informações sobre os átomos individuais.

Com preocupações similares, Piaget fala que o objetivo da ciência é a "conquista do objeto", um objeto que existe independentemente dela, ainda que "se modifique à medida que tem lugar a conquista proveniente de uma crescente aproximação". Conhece-se o objeto por meio de um processo em que se conjugam viagens à abstração e viagens à periferia e ao interior dele.

A ciência é necessária por ser uma ferramenta espiritual que amplia nossa lucidez, abre horizontes para o compreender e o agir sem as amarras das crenças, das certezas estabelecidas, permitindo identificarmos os limites impostos pela precariedade de nossos sentidos.

Conhecer limites não é uma carência do humano, ser finito: ao invés de anunciar impossibilidades, constitui-se em abertura de possibilidades. Albert Jacquard (1996, p.121) salienta que a curiosidade "perante o universo fez-nos descobrir realidades que nenhum animal poderá jamais suspeitar existirem; os nossos sentidos só nos permitem o acesso a uma pequena parte das informaçóes enviadas pelas estrelas: fomos capazes de as completar, de descobrir pulsares, de imaginar buracos negros, de "ver" um céu que nenhum olho poderia descobrir". 


\section{A ciência como sabedoria de vida}

Crer é morrer, pensar é duvidar;

A crença é o sono e o sonho do intelecto

A fé é isto: o pensamento

A querer enganar-se eternamente.

(Fernando Pessoa)

As respostas para "quem somos?", "de onde viemos?", "para onde vamos?” foram formuladas, de primeira mão, colocando-nos na situação de novatos e desenraizados, em relação ao mundo natural: herdeiros de graças e de maldições, jamais como responsáveis pelo desafio de inventar o humano, sob as intempéries do acaso e da necessidade.

Para explicar "quem somos", sedimentamos crenças, apegamo-nos a poderes, alimentamos a arrogância e cultivamos a predisposição mental para a vida, sob as asas da certeza. Erich Fromm, em Análise do homem, fala da necessidade psicológica que as pessoas têm de explicaçôes duráveis e da segurança de estarem em um mundo previsível, em que nada ocorra por acaso, governado por algum ente poderoso.

A margem do mundo assim arrumado, olhos visionários começaram a enxergar outras realidades e a levantar novas hipóteses, fazendo germinar dúvidas... Com isso, nasce a ousadia para se perceber que estamos em um mundo desconhecido, como diz Jacques Monod (2002, p. 120): "o homem sabe, finalmente, que está só na imensidão indiferente do universo, donde emergiu por acaso. Nem o seu destino nem o seu devir estão escritos em parte alguma. A ele cabe escolher entre o Reino e as trevas".

À medida que o castelo de certezas vai se desfazendo, a arrogância humana sofre alguns arranhões, como salienta o paleontólogo Stephen Gould (2001, p. 33):

Já tive muitas ocasiōes para citar a incisiva observação de Freud, quase pesarosa, de que todas as grandes revelaçóes na história da ciência tiveram como tema comum, entre tanta diversidade, a sucessiva derrubada da arrogância humana, de um pedestal depois do outro, onde pontificávamos com a nossa anterior convicção cósmica. (...) Houve uma época em que pensávamos que vivíamos no corpo central de um universo limitado, até que Copérnico, Galileu, Newton identificaram a Terra como um insignificante satélite de uma estrela marginal. Então nós nos confortamos imaginando que, não obstante, Deus escolhera essa localização periférica para criar um organismo único à Sua imagem - até que chegou Darwin e "nos relegou à condição de descendente de um mundo animal”.

Bohr (1995, p. 30), passeando por essas reflexôes, pergunta:

Quão imperiosa não foi também a advertência que recebemos, em nossa época, sobre a relatividade de todos os juízos humanos, ao uso não ambíguo até mesmo de nossos conceitos mais elementares, como o espaço e o tempo, os quais, ao revelarem a dependência especial em que estão todos os fenômenos físicos do ponto de vista do observador, tanto contribuíram para a unidade e a beleza de toda a nossa visão de mundo?

A ciência tem o caráter de espaço alternativo, lugar privilegiado para se investir energia criativa, na busca de possibilidades ainda não vistas e, também, para interrogar muitas de nossas preconcepções. Por isso, ela acaba sendo uma referência fundamental para os olhares que buscam enxergar além dos domínios da dependência. Como instrumento espiritual que 
permite uma melhor coordenação para a leitura de mundo, parece ser ela a mais promissora fonte de inspiração, para se pensar a condição humana.

Pois, como afirma Einstein (1981, p. 12), “é a pessoa humana, livre, criadora e sensível que modela o belo e exalta o sublime, ao passo que as massas continuam arrastadas por uma dança infernal de imbecilidade e de embrutecimento".

Schrödinger (1996, p. 102) recomenda: "mantenha-se em contato com a vida - não tanto com a vida prática, mas com o pano de fundo ideal da vida, que é cada vez mais importante. E mantenha a vida em contato consigo". Essa é a importante lição que o espírito da ciência e o das artes nos oferecem, acerca de nossa verdadeira vocação: além das questôes práticas e úteis do cotidiano, existem belos espaços para as pessoas investirem energia criativa e enfrentarem desafios intelectuais.

\section{Passos em direção à ciência}

$\mathrm{O}$ que serve à vida imobiliza-a. O que serve ao espírito põe-no em movimento. (Gastón Bachelard)

Caminhar em direção à ciência é uma atitude que se liga ao "abrir-se" para o conhecer e à sensibilidade para colocar em dúvida as verdades que carregamos. A sucessão de revoluções do pensamento, que marcam o percurso de construção da ciência, constitui-se em uma mensagem de alerta acerca do caráter perecível do conhecimento e dos limites do humano.

Por isso, a iniciação à ciência é um passo em direção à incerteza e ao autoconhecimento, à tomada de consciência de que "muitas nuvens que cobrem a nossa visão são de nossa própria lavra: preconceitos sociais e culturais, preferências psicológicas e limitaçôes mentais (quanto a modos universais de pensamento, não apenas quanto à burrice individual)" (GOULD, 2001, p. 22).

Ela não se situa no nível do fazer, é uma forma de pensar e de dialogar com o mundo. Por isso, Bachelard (1996, p. 289) lembra-nos de que "seria mais simples ensinar só o resultado. Mas o ensino dos resultados da ciência nunca é ensino científico. Se não for explicada a linha de produção espiritual que levou ao resultado, pode-se ter a certeza de que o aluno vai associar o resultado a suas imagens mais conhecidas".

É uma preparação para a renúncia à comodidade espiritual de se viver em um mundo previsível e conhecido, a partir de sábias leituras. Ian Stewart (1991, p. 28), sobre as previsões, as certezas e a nossa arrogância cognitiva, diz ficar desgostoso "com os cosmólogos que afirmam já conhecerem as origens do Universo, tudo bem arrumadinho”. E com os políticos que nos asseguram que "uma boa dose de monetarismo nos fará bem e que alguns milhôes de desempregados representarão apenas um inconveniente insignificante".

A aproximação à ciência conta com dois pilares importantes: a reflexão ontológica e a epistemológica. No emaranhado de informações em que vivemos, a ciência muitas vezes é apontada como acervo de boas respostas e como algo de natureza técnico-instrumental. E, em um desvio epistemológico, a sua iniciação é percebida como o exercício de retenção de enunciados. O desafio é situá-la, no âmbito escolar, como estado de espírito avesso ao apego ao conhecimento. Seu élan repousa na mobilidade do conhecer, que tem larga familiaridade com o desaprender e com a desenvoltura de tirar de pedestais imponentes verdades.

Bachelard (1996, p. 17) chama nossa atenção para a tomada de consciência do caráter contingente do conhecimento, quando fala que, no fundo, "o ato de conhecer dá-se contra um conhecimento anterior, destruindo conhecimentos mal estabelecidos, superando o que no próprio espírito, é obstáculo à espiritualização". Ele acrescenta: 
O conhecimento do real é luz que sempre projeta algumas sombras. Nunca é imediato e pleno. As revelaçôes do real são recorrentes. O real nunca é "o que se poderia achar" mas é sempre o que se deveria ter pensado. O pensamento empírico torna-se claro depois, quando o conjunto de argumentos fica estabelecido. Ao retomar um passado cheio de erros, encontra-se a verdade num autêntico arrependimento intelectual.

Nesses versos de Fernando Pessoa, podemos viajar pelos mesmos horizontes:
A verdade, se ela existe,
ver-se-á que só consiste
na procura da verdade,
porque a vida é só metade.

Em síntese, a aproximação à ciência é um exercício espiritual. Implica a renovação da forma de equilibrar o mundo interior - das intuições, crenças e reminiscências explicativas - e o mundo exterior - o território das observaçôes, do confronto com a realidade. Um desafio desse porte poderia, na educação formal, transitar pelos diferentes níveis de escolarização, do ensino fundamental à pós-graduação, tendo como pano de fundo a condição humana e as múltiplas relações entre ciência, arte e filosofia.

\section{Considerações finais}

A ciência não se constitui em um aparato de busca da verdade; antes disso, ela amplia nossa capacidade de reconhecer o falso. Ou, como disse Aldous Huxley, o método científico "nada mais é do que o trabalho normal da mente humana quando está empenhada em corrigir seus erros". Isso situa a ciência como uma forma especial de empregar a inteligência, de tomada de consciência de quão enganosas podem ser nossas conviç̧ões, quando não submetidas constantemente à prova, ao confronto com o mundo exterior.

O espírito da ciência, como uma espécie de disciplina do pensamento, poderia ser importante ferramenta emancipatória para o não-cientista. Abriria horizontes para diminuir o apego à garantia de controle vindo de fora, o que implicaria maior preservação da singularidade de cada pessoa e o distanciamento do cadinho que leva os menos despertos à massificação.

Ao apreciar curiosamente as coisas do dia-a-dia, respondemos algumas perguntas de forma imediata, lembrando-nos de lições recebidas, de recomendações técnicas, de modelos já vistos... Porém, as mais gratificantes são aquelas que exigem de nós, além da técnica, a arte. Ou seja, aquele tom de criatividade que se distancia bastante de tudo o que já havíamos visto, que só é possível quando o nosso pensamento ganha asas e se orienta por uma disciplina interior.

$\mathrm{Na}$ escola, a aproximação à ciência seria um processo de múltiplos rodeios, que poderia tomar como metáfora o paradoxo de Zenão sobre Aquiles e a tartaruga. Sucessivas aproximações, cada vez mais perto de um convívio feliz com as dúvidas, com o acaso, e a tomada de consciência das limitações do humano e da necessidade de ferramentas de coordenação do pensamento. 


\section{Adriano Rodrigues Ruiz}

\section{Referências}

AUGER, P. Os métodos e os limites do conhecimento científico. In: BORN, M. et al. Problemas da fisica moderna. São Paulo: Perspectiva, 2000.

BOHM, D. A totalidade e a ordem implicada: uma nova percepção da realidade. São Paulo: Cultrix, 2001.

BOHR, N. Física atômica e o conhecimento humano. Rio de Janeiro: Contraponto, 1995.

BRONOWSKI, J. O olho visionário. Brasília: Editora da Universidade de Brasília, 1998.

EINSTEIN, A. Como vejo o mundo. Rio de Janeiro: Nova Fronteira, 1981.

FROMM, E. Análise do homem. São Paulo: Círculo do Livro, [s.d.].

GOULD, S. J. Lance de dados. Rio de Janeiro: Record, 2001.

HEGENBERG, L. Significado e conhecimento. São Paulo: EPU, 1975.

HEISENBERG, W. Páginas de reflexão e auto-retrato. Lisboa: Gradiva, 1990.

JACQUARD, A. Inventar o homem. Lisboa: Terramar, [1990].

MONOD, J. O acaso e a necessidade. Lisboa: Europa-América, 2002.

PESSOA, F. Poemas. Rio de Janeiro: Nova Fronteira, 1985.

PIAGET, J. Sobre pedagogia. São Paulo: Casa do Psicólogo, 1998.

PRIGOGINE, I.; STENGERS, I. A nova aliança. Brasília: Editora da Universidade de Brasília, 1997.

SCHRÖDINGER, E. A natureza e os gregos e ciência e humanismo. Lisboa: Edições 70, 1996. O que é a vida? São Paulo: Editora da Unesp, 2001.

STEWART , I. Deus joga dados? Rio de Janeiro: Zahar, 1991.

WIENER, N. Cibernética e sociedade: o uso humano dos seres humanos. São Paulo: Cultrix, 1970.

Artigo recebido em agosto de $2004 \mathrm{e}$ selecionado para publicação em setembro de 2005. 